\title{
Solving Practical Economic Dispatch Problems Using Improved Artificial Bee Colony Method
}

\author{
Belkacem MAHDAD \\ Department of Electrical Engineering, Biskra University, Algeria \\ Email: bemahdad@mselab.org \\ Kamel Srairi \\ Department of Electrical Engineering, Biskra University, Algeria \\ Email: ksrairi@mselab.org
}

\begin{abstract}
This paper presents an improved artificial bee colony (IABC) optimization method to solving practical economic dispatch taking into account the nonlinear generator characteristics such as valve-point loading effects. In order to exploit the performance of this new variant based $A B C$ method to solving practical economic dispatch, a new local search mechanism (LSM) associated to the original $\mathrm{ABC}$ algorithm; it allows exploiting effectively the promising region to locate the best solution. The proposed approach has been examined and applied to many practical electrical power systems, the 13 generating units, and to the large electrical system with 40 generating units considering valve point loading effects. From the different case studies, it is observed that the results compared with the other recent techniques demonstrate the potential of the proposed approach and show clearly its effectiveness to solve practical and large ED.
\end{abstract}

Index Terms - Global optimization, Artificial bee colony, Economic dispatch, Optimal power flow, Valve point effect, Prohibited zones, Local search.

\section{INTRODUCTION}

During the last two decades, the interest in applying global optimization methods in power system field has grown rapidly. Economic dispatch strategy is one of the fundamental issues of power system operation and planning, its main objective is to schedule the committed generating units of a power system by optimizing a particular objective function, while satisfying certain specified operating constraints. In its most general formulation, the economic power dispatch (EPD) is a nonlinear, nonconvex, large-scale problem with both continuous and discrete control variables. It becomes even more complex when practical generators constraints (prohibited zones, valve point effects, pollution control) are taken in consideration [1]. The literature on the application of the global optimization in the OPF problem is vast and [1] represents the major contributions.

Huge number mathematical optimization techniques have been employed for solving the economic dispatch problem, this first category includes, linear programming (LP), nonlinear programming (NLP), quadratic programming $(\mathrm{QP})$, and interior point methods [2-3]. All these techniques rely on initial condition and convexity to find the global optimum; methods based on these assumptions do not guarantee to find the global optimum when considering practical of generator constraints (Prohibited zones, Valve point effect, and multi-fuel options), in [4], authors present a review of the major contributions in this area.

The second category includes many heuristique and stochastic optimization methods known as global optimization techniques (GOT). Many evolutionary algorithms such as the genetic algorithm (GA) [5], particle swarm optimization (PSO) [6], simulated annealing (SA) [7], tabu search (TS) [8], ant colony optimization (ACO) [9], and differential evolution (DE) [10], were proposed to solve the practical economic dispatch problem. In [1]-[11], authors present the major contributions of this second category in power system operation and control.

The third category includes, a variety of hybrid methods based conventional methods (mathematical methods) and global optimization techniques, like genetic algorithm (GA) and quadratic programming (GA-QP), or combination of artificial techniques with metaheuristic methods, like: Fuzzy logic and genetic algorithm (FuzzyGA), artificial neural network and genetic algorithm (ANN-GA), Fuzzy logic and particle swarm optimization (Fuzzy-PSO) [12]. In the literature various modified global optimization methods have been proposed to solving various problems related to power system operation and control, the major contributions related to this category reviewed by authors in [11].

Recently, a new family of global optimization methods, have been developed and applied with success to solving complex optimization methods such as; Harmony search [13], biogeography based optimization method [14], honey bee algorithm [15], teaching learning based optimization (TLBO) [16], and Fuzzy-TLBO [17]. Artificial Bee Colony (ABC) algorithm [18-19-20] is one of the most recently introduced swarm-based algorithms. $\mathrm{ABC}$ simulates the intelligent foraging behavior of a honey bee swarm. This paper presents an improved artificial bee colony algorithm for the solution of practical and large economic dispatch considering valve point loading effects and power transmission loss. 


\section{MATHEMATiCAl Formulation OF ACTIVE POWER PLANNING}

The main strategy of economic dispatch (ED) is to minimize the total generation cost of power system but still satisfying specified constraints (generators constraints and security constraints).

\section{A. Simple objective function}

For optimal active power dispatch, the objective function $f$ is the total generation cost expressed as follows:

$$
\text { Min } f=\sum_{i=1}^{N G}\left(a_{i}+b_{i} P_{g i}+c_{i} P_{g i}^{2}\right)
$$

Where $N G$ is the number of thermal units, $P_{g i}$ is the active power generation at unit $\mathrm{i}$ and $a_{i}, b_{i}$ and $c_{i}$ are the cost coefficients of the $i^{\text {th }}$ generator.

\section{B. Constraints}

\section{Equality constraints: Power balance constraints}

The total power generation must cover the required total demand $P_{D}$ and the active power loss in transmission line $P_{\text {loss }}$, the equality constraint expressed as follows:

$$
\sum_{i=1}^{N G} P_{g i}-P_{D}-P_{l o s s}=0
$$

C. The inequality constraints: Generating units security constraints

- Upper and lower limits on the active power generations:

$$
P_{g i}^{\min } \leq P_{g i} \leq P_{g i}^{\max }
$$

$P_{g i}^{\min }$ and $P_{g i}^{\max }$ are the minimum and maximum outputs of the ith generation unit;

\section{Objective function with valve point effect}

The valve-point loading is taken in consideration by adding a sine component to the cost of the generating units [12-14].

Typically, the fuel cost function of the generating units with valve-point loading is represented as follows:

$$
f_{T}=\sum_{i=1}^{N G}\left(a_{i}+b_{i} P_{g i}+c_{i} P_{g i}^{2}+\left|d_{i} \sin \left(e_{i}\left(P_{g i}^{\min }-P_{g i}\right)\right)\right|\right)
$$

$d_{i}$ and $e_{i}$ are the cost coefficients of the unit with valve-point effects. The input-output performance curve for a typical thermal unit can be represented as shown in figure 1 .

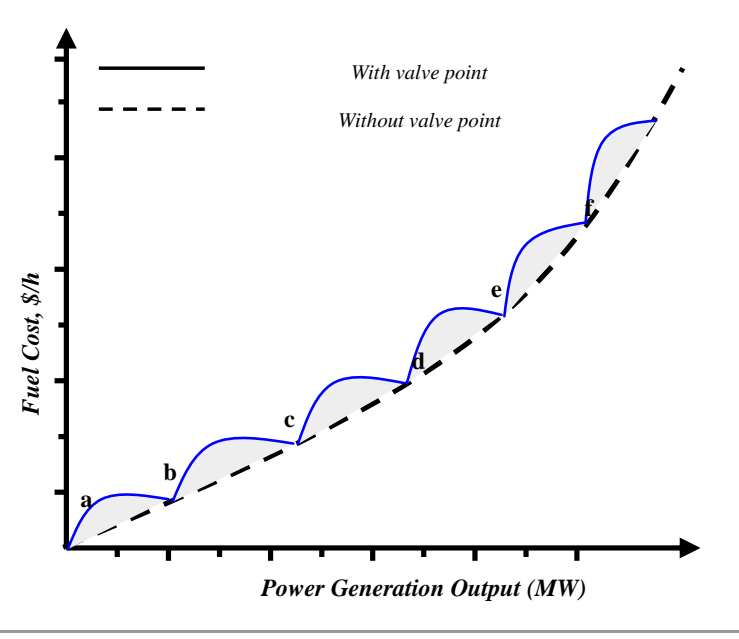

Fig. 1. Fuel cost characteristic under valve-point loading effects.

\section{ARtificial BeE COLONy Optimization Method}

Artificial Bee Colony (ABC) algorithm, proposed by Karaboga in 2005 for real parameter optimization, is a recently introduced optimization algorithm and simulates the foraging behavior of bee colony [18] for unconstrained optimization problems [19].

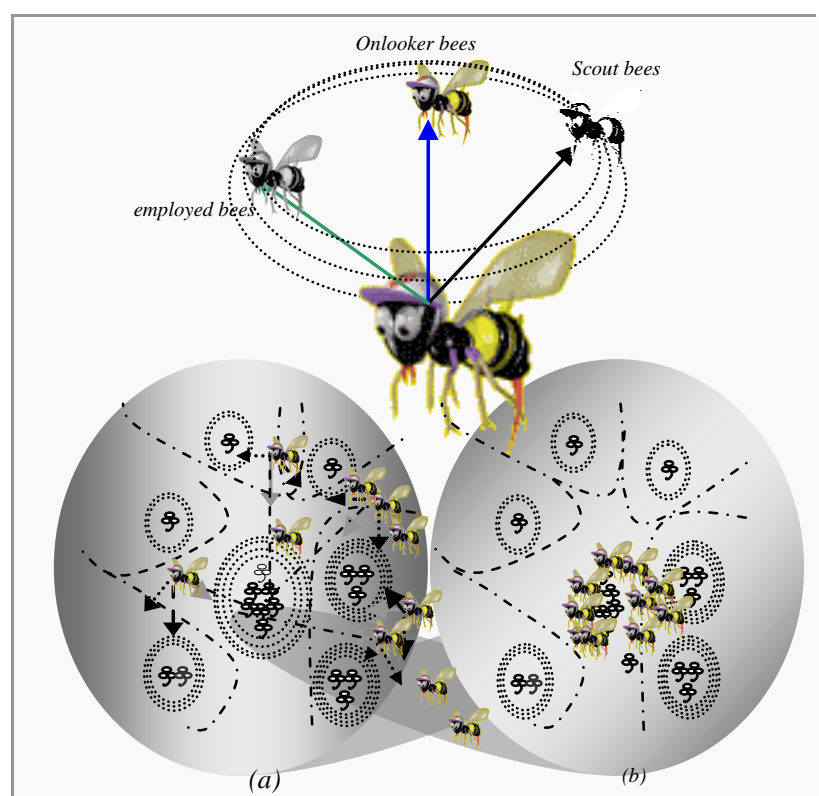

Fig. 2. Basic mechanism search of ABC: a) Initial situation, b) Final situation.

\section{A. Mechanism search of the original $A B C$}

As well illustrated in figure 2, the colony of artificial bees consists of three groups of bees called employed bees, onlookers and scouts. While a half of the colony consists of the employed artificial bees, the other half includes the onlookers.

There is only one employed bee for every food source. It means that the number of employed bees is equal to the number of food sources around the hive. The basic mechanism search of $\mathrm{ABC}$ is well presented in figure 2 . 


\section{B. Artificial Bee Colony algorithm}

The main steps of the algorithm described as below:

\section{1: Initialize Population}

2: repeat

3: $\mid$ Place the employed bees on their food sources

4: Place the onlooker bees on the food sources

depending on their nectar amounts

5: Send the scouts to the search area for discovering new food sources

6: Memorize the best food source found so far

7: until Stopping condition

The steps of the basic ABC algorithm can be explained in details as follow:

\section{Producing initial food source sites}

Initial food sources are produced randomly within the range of the boundaries of the control parameters.

$$
\begin{aligned}
& x_{i, j}^{(0)}=x_{j}^{(L)}+\operatorname{rand}[0,1] *\left(x_{j}^{(U)}-x_{j}^{(L)}\right) ; \\
& i=1,2,3 \ldots . . N P \\
& j=1,2,3 \ldots . . D
\end{aligned}
$$

Where,

$N P \quad$ : is the number of food sources;

$D:$ is the number of decision variables;

$\operatorname{rand}[0,1]$ : denotes a uniformly distributed random value between 0 and 1 .

$x_{j}^{(L)}$ and $x_{j}^{(U)}$ are lower and upper bounds of the jth decision variable;

\section{Searching process}

In the second step of the algorithm, for each employed bee, a new source is produced by:

$$
v_{i j}=x_{i j}+\varphi_{i j}\left(x_{i j}-x_{k j}\right) \text {, }
$$

Where, $k \in\{1,2, \ldots . ., N P\}, j \in\{1,2, \ldots, D\}, \varphi_{i j}$ is a uniformly distributed real random number within the range $[-1,1]$, it controls the production of neighbour food sources around $x_{i j}$ and represents the comparison of two food positions visually by a bee.

The total number of employed bee equals to the half of the number of food source. In this study the value of the control parameter exceeding its boundary (active power generation in this case) is set to its limits based on the following conditions:

$$
\begin{array}{ll}
\text { if } \quad x_{i} \succ x_{i}^{U} & \text { then } x_{i}=x_{i}^{U}, \\
\text { if } \quad x_{i} \succ x_{i}^{L} & \text { then } x_{i}=x_{i}^{L}
\end{array}
$$

\section{Evaluation phase}

3.1 Exchange information: In this stage the employed bees share their information related to the nectar amounts and the positions of their sources with the onlooker bees on the dance area.
3.2 Fitness evaluation: An onlooker bee evaluates the nectar information taken from all employed bees and chooses a food source site with a probability related to its nectar amount.

3.3 Selection probability: The probabilistic selection depends on the fitness values of the solutions in the population. In the original $\mathrm{ABC}$ this probabilistic selection scheme formulated based on (7), as the nectar amount of food sources (the fitness of solutions) increases, the number of onlookers visiting them increases, too.

$$
p_{i}=\frac{a \cdot \text { fitness }_{i}}{\max (\text { fitness })}+b
$$

Where, fitness $_{i}$ is the fitness of the solution $x_{i}$.

\section{Improved Artificial Bee Colony (IABC)}

The basic disadvantage of the original ABC algorithm is that it may fail to locate the global optimum and provide near optimum solution, in order to exploit the performance of this new method to enhance the solution quality to solving practical economic dispatch a new local search mechanism associated to the original $\mathrm{ABC}$ algorithm it allows exploiting effectively the promising region to locate the best solution.

Figure 3 shows the basic principle of the local mechanism search coordinated with the original ABC algorithm; figure 4 shows the flowchart of the proposed improved $\mathrm{ABC}$ using simple dynamic local search mechanism.

$$
a_{i}=\left[x_{1}, x_{2}, \ldots ., x_{n}\right]_{1 . n g}, b_{i}=\left[y_{1}, y_{2}, \ldots ., y_{n}\right]_{1 . n g}
$$

$-a_{i}, b_{i}$ are the initial lower and upper limits on the active power generations constraints.

The best solution found ( $P g_{i}^{\text {best }}$ ) using $\mathrm{ABC}$ is considered as an initial solution for the local search procedure (LSP).

1-Generate new power limits according to the following equations:

$$
\begin{gathered}
\Delta_{i}^{\mathrm{min}}=P g_{i}^{\text {best }}-\text { Rand }(.)\left(P g_{i}^{\text {best }}-P g_{i}^{\mathrm{min}}\right) \\
\Delta_{i}^{\mathrm{max}}=P g_{i}^{\text {best }}-\text { Rand }(.)\left(P g_{i}^{\mathrm{max}}-P g_{i}^{\text {best }}\right)
\end{gathered}
$$

Where;

$\Delta_{i}^{\min }, \Delta_{i}^{\max }$ are the two estimated regions.

$a_{i}^{\text {new }}, b_{i}^{\text {new }}$ are the new estimated lower and upper limits on the active power generation constraints.

2- The objective function (minimum fuel cost) values are calculated:

- New data base is generated at each level: $\left[a_{i}, b_{i}^{\text {new }}\right]$, $\left[a_{i}^{\text {new }}, b_{i}\right],\left[a_{i}^{\text {new }}, b_{i}^{\text {new }}\right]$

- Save the new range $a_{i}^{\text {new }}, b_{i}^{\text {new }}$ as an initial search range to the next generation, 
- Save the new feasible generation units limits $\left(P g_{i}^{\min }(\right.$ new $), P g_{i}^{\max }($ new $\left.)\right)$.

3-Repeat processes search until the last level is reached:

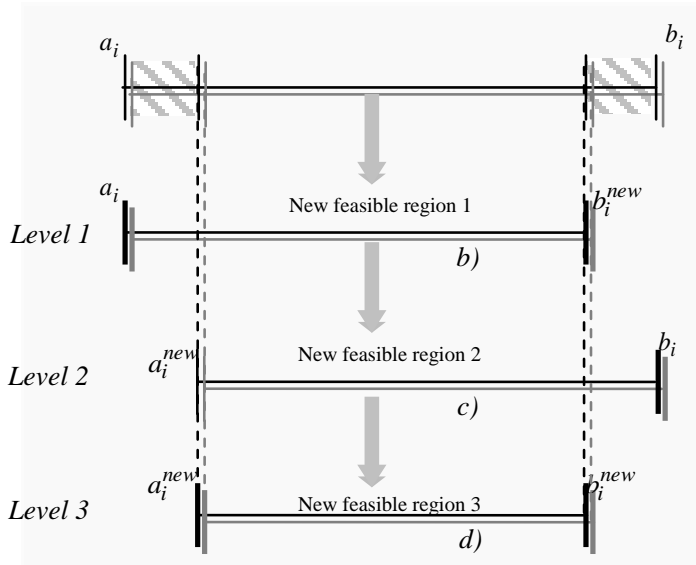

Fig. 3. Local search mechanism: a): initial lower and upper bounds, b), c), d) are the new estimated generated bounds.

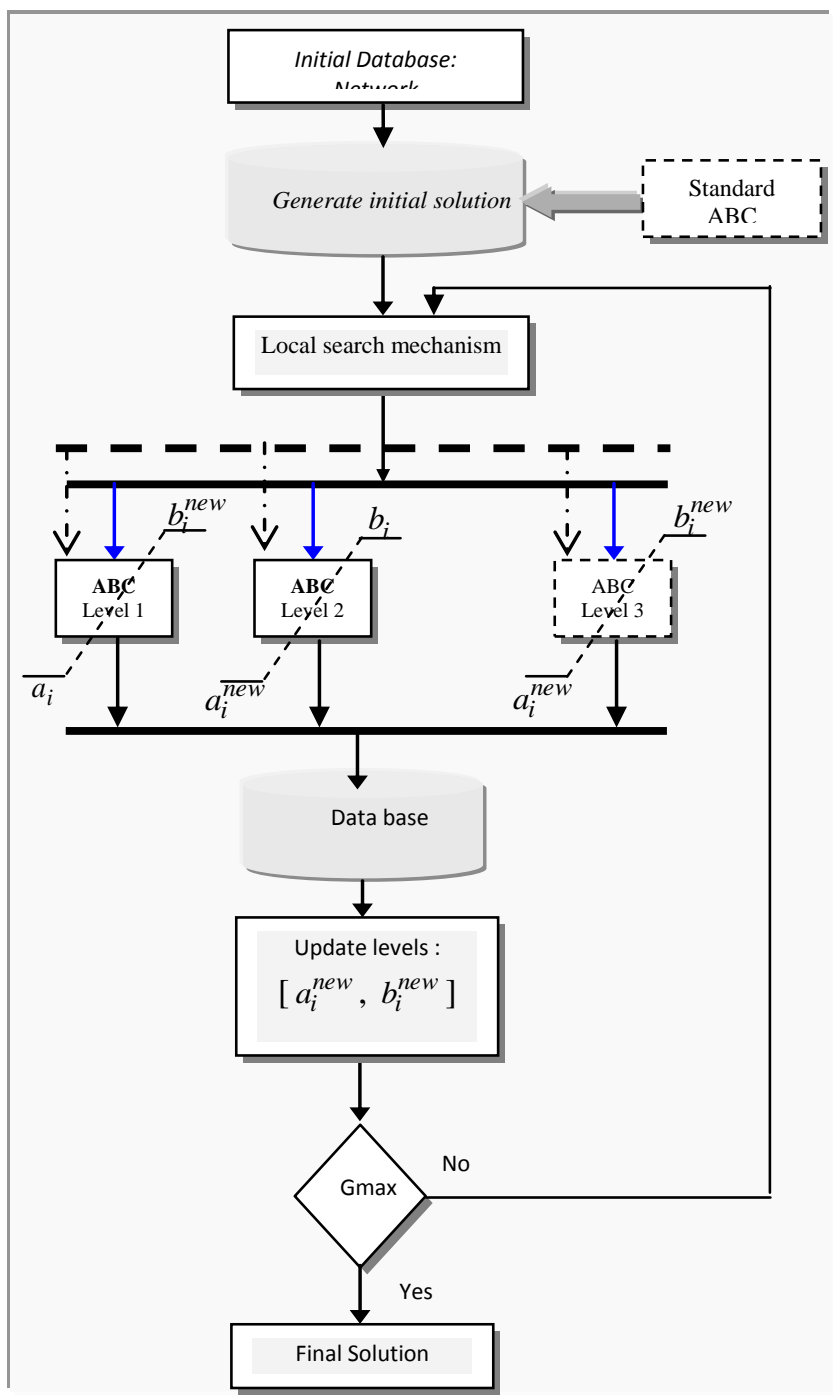

Fig. 4. Proposed I ABC based dynamic local search mechanism.

\section{Parameters settings of IABC}

The initial values of IABC parameters are selected as depicted in Table 1:

Table. 1 The Parameters USEd in the Proposed Algorithm

\begin{tabular}{|c|c|c|c|}
\hline Parameter & Explanation & Value & \\
\hline$N P$ & colony size & $20-30$ & $\begin{array}{l}\text { Based on the } \\
\text { problem size }\end{array}$ \\
\hline Limit & & 20 & $\begin{array}{l}\text { Based on the } \\
\text { problem size }\end{array}$ \\
\hline $\begin{array}{l}\text { Food } \\
\text { Number }\end{array}$ & $\begin{array}{l}\text { the number of } \\
\text { food sources }\end{array}$ & $N P / 2$ & \\
\hline$a$ & $\begin{array}{l}\text { Coefficient } \\
\text { associated to } \\
\text { probabilistic } \\
\text { selection }\end{array}$ & 0.85 & \\
\hline$b$ & & 0.15 & \\
\hline Max cycle & $\begin{array}{l}\text { Maximum } \\
\text { Generation }\end{array}$ & $100-500$ & $\begin{array}{l}\text { Based on the } \\
\text { problem size }\end{array}$ \\
\hline
\end{tabular}

Table 2. ECONOMIC DISPATCH RESULTS FOR 13-GENERATING UNITS USING THE PROPOSED APPROACH: PD $=1800 \mathrm{MW}$

\begin{tabular}{|c|c|c|c|}
\hline$N^{\circ}$ & $\begin{array}{c}\text { Our } \\
\text { approach: IABC }\end{array}$ & PS [24] & QPSO [25] \\
\hline 1 & 628.2986 & 538.5587 & 538.560 \\
\hline 2 & 149.0807 & 224.6416 & 224.70 \\
\hline 3 & 223.8643 & 149.8468 & 150.09 \\
\hline 4 & 109.6659 & 109.8666 & 109.87 \\
\hline 5 & 109.6171 & 109.8666 & 109.87 \\
\hline 6 & 109.8320 & 109.8666 & 109.87 \\
\hline 7 & 60.0000 & 109.8666 & 109.87 \\
\hline 8 & 109.8660 & 109.8666 & 109.87 \\
\hline 9 & 109.7754 & 109.8666 & 109.87 \\
\hline 10 & 40.0000 & 77.4666 & 77.41 \\
\hline 11 & 40.0000 & 40.2166 & 40.00 \\
\hline 12 & 55.0000 & 55.0347 & 55.01 \\
\hline 13 & 55.0000 & 55.0347 & 55.01 \\
\hline TP (MW) & 1800 & 1800 & 1800 \\
\hline Cost $(\$ / / h)$ & 17964.469 & 17969.17 & 17969.01 \\
\hline
\end{tabular}

\section{CAse Studies}

In order to investigate the robustness and performance of the proposed variant termed IABC algorithm, two standard practical electrical test systems are considered, 13 generating units and to the 40 generating units considering valve-point loading effects. 


\section{A Test System 1: 13 generating units with valve loading effects}

This test system consists of 13 generating units with consideration of valve-point loading effects, the total load demand expected to be satisfied was $\mathrm{PD}=1800 \mathrm{MW}$. The power losses are ignored in this case. The convergence of the IABC process is shown in Figure 5. The best results were compared to many recent global optimization techniques. Table 2 shows the optimal solutions obtained by the proposed approach based IABC method for the 13 generating units. Table 3 shows a comparative study with various recent global optimization methods cited in the literature [24-25]. Figure 6 shows convergence characteristics comparison of $\mathrm{ABC}$ and the proposed IABC.

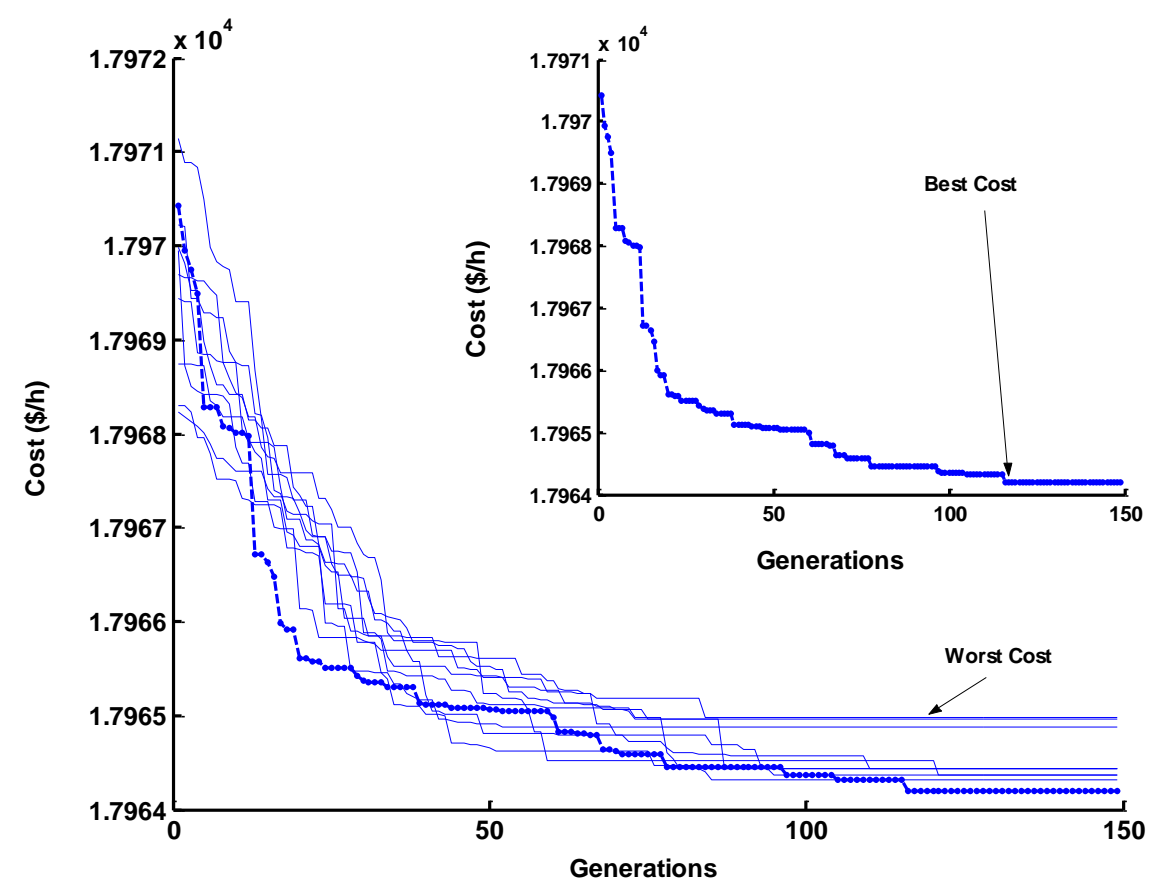

Fig. 5. Convergence characteristic: test system 1: 13 generating units using the proposed IABC.

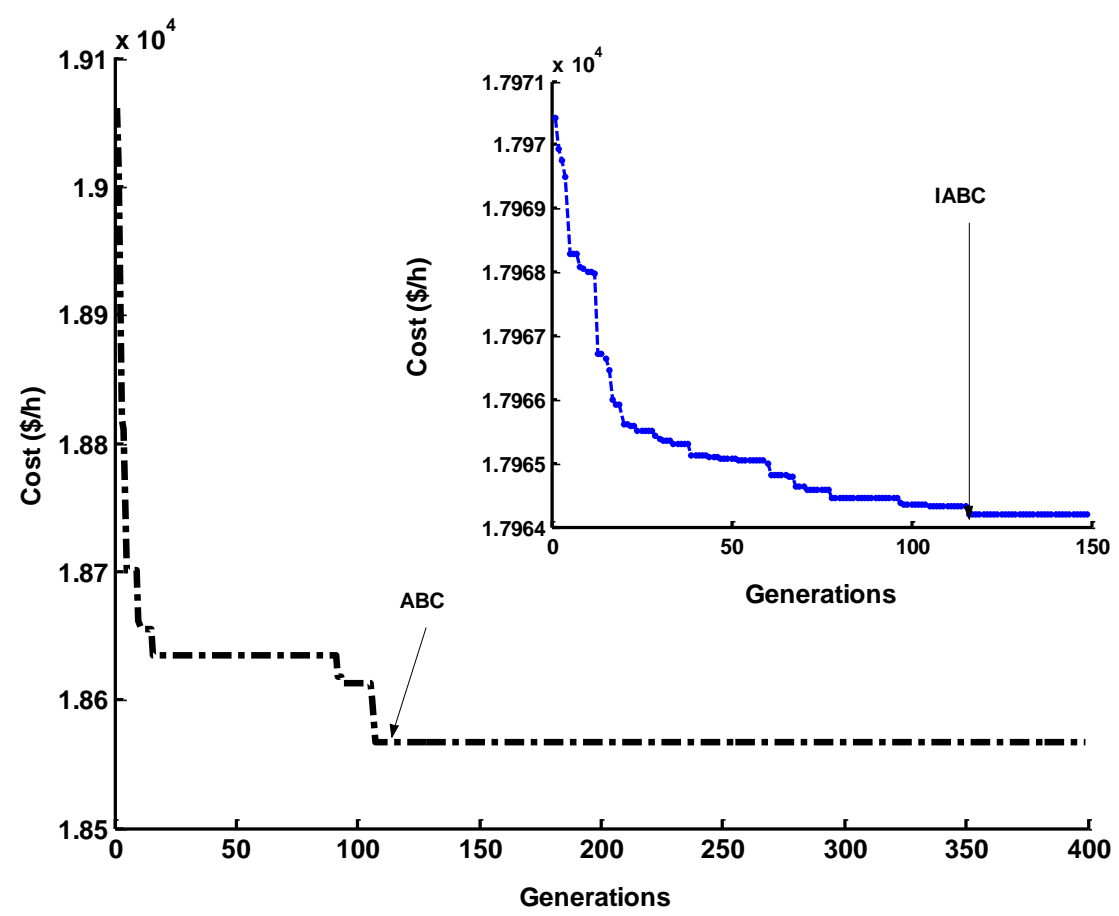

Fig. 6. Convergence characteristic: test system 1: using $\mathrm{ABC}$ and $\mathrm{IABC}$. 
Table 3. COMPARISON OF BEST RESULTS FOR FUEL COSTS: CASE STUDY 13 THERMAL UNITS.

\begin{tabular}{c|cc}
\hline $\begin{array}{c}\text { Methods: } \\
\text { Ref }[28]\end{array}$ & $\begin{array}{c}\text { Minimum Cost } \\
(\$ / h)\end{array}$ & $\begin{array}{c}\text { Average } \\
\text { Cost }(\$ / h)\end{array}$ \\
\hline CEP & 18048.21 & 18190.32 \\
FEP & 18018.00 & 18200.79 \\
MFEP & 18028.09 & 18192.00 \\
IFEP & 17994.07 & 18127.06 \\
EGA & 18019.15 & 18144.95 \\
FIA & 18014.61 & 18136.97 \\
SPSO & 17988.15 & 18102.48 \\
QPSO & 17969.01 & 18075.11 \\
Proposed & $\mathbf{1 7 9 6 4 . 4 6 9}$ & $\mathbf{1 7 9 6 5 . 1 2 4}$ \\
approach: IABC & & \\
\hline
\end{tabular}

B. Test System 2: Large system: 40 generating units with valve-point loading effects

A system with 40 generators with the valve-point loading effects was studied in this third case. Total load demand of the system is $10500 \mathrm{MW}$. This is a larger system, the number of local optima, complexity and nonlinearity to the solution procedure is enormously increased. The convergence characteristic of the IABC is shown in figure 7; the best results of the proposed approach compared with other methods are illustrated in Tables 4-5, shows clearly the superiority of the proposed approach.

Table 4. ECONOMic DisPatch Results For 40-Generating UNITS USING THE PROPOSED APPROACH: PD =10500 MW

\begin{tabular}{|c|c|c|c|c|c|c|c|}
\hline \multirow[b]{2}{*}{$\mathbf{N}^{\circ}$} & \multicolumn{3}{|c|}{$P g_{i}(\mathrm{MW})$} & & \multicolumn{3}{|c|}{$P g_{i}(\mathrm{MW})$} \\
\hline & [QPSO] [25] & [DEBBO] [14] & Our Approach & $\mathrm{N}^{\circ}$ & [QPSO] [25] & [DEBBO] [14] & Our Approach \\
\hline 1 & 111.20 & 110.7998 & 110.8266 & 21 & 523.28 & 523.2794 & 523.2788 \\
\hline 2 & 111.70 & 110.7998 & 110.8333 & 22 & 523.28 & 523.2794 & 523.2796 \\
\hline 3 & 97.40 & 97.3999 & 97.3988 & 23 & 523.29 & 523.2794 & 523.2813 \\
\hline 4 & 179.73 & 179.7331 & 179.7341 & 24 & 523.28 & 523.2794 & 523.2794 \\
\hline 5 & 90.14 & 87.9576 & 87.8002 & 25 & 523.29 & 523.2794 & 523.2811 \\
\hline 6 & 140.00 & 140.000 & 139.9999 & 26 & 523.28 & 523.2794 & 523.2794 \\
\hline 7 & 259.60 & 259.5997 & 259.5997 & 27 & 10.01 & 10.00 & 10.0000 \\
\hline 8 & 284.80 & 284.5997 & 284.6077 & 28 & 10.01 & 10.00 & 10.0000 \\
\hline 9 & 284.84 & 284.5997 & 284.6005 & 29 & 10.00 & 10.00 & 10.0000 \\
\hline 10 & 130.00 & 130.000 & 130.0000 & 30 & 88.47 & 97.000 & 92.6787 \\
\hline 11 & 168.80 & 168.7998 & 168.8012 & 31 & 190.00 & 190.000 & 190.0000 \\
\hline 12 & 168.80 & 94.000 & 168.7998 & 32 & 190.00 & 190.000 & 190.0000 \\
\hline 13 & 214.76 & 214.7598 & 214.7597 & 33 & 190.00 & 190.000 & 190.0000 \\
\hline 14 & 304.53 & 394.2794 & 394.2794 & 34 & 164.91 & 164.7998 & 164.8037 \\
\hline 15 & 394.28 & 394.2794 & 394.2790 & 35 & 165.36 & 200.00 & 164.7999 \\
\hline 16 & 394.28 & 304.5196 & 304.5198 & 36 & 167.19 & 200.00 & 164.8005 \\
\hline 17 & 489.28 & 489.2794 & 489.2794 & 37 & 110.00 & 110.0000 & 110.0000 \\
\hline 18 & 489.28 & 489.2794 & 489.2794 & 38 & 107.01 & 110.0000 & 110.0000 \\
\hline 19 & 511.28 & 511.2794 & 511.2798 & 39 & 110.00 & 110.0000 & 110.0000 \\
\hline 20 & 511.28 & 511.2794 & 511.2795 & 40 & 511.36 & 511.2794 & 511.2797 \\
\hline TP (MW) & & & & & 10,500 & 10,500 & 10,500 \\
\hline TC (\$/h) & & & & & 121448.21 & 121420.89 & 121414.749 \\
\hline
\end{tabular}


Table 5. COMPARISON OF THE PROPOSED APPROACH WITH OTHER GLOBAL OPTIMIZATION METHODS 40-GENERATING UNITS PD =10500 MW

\begin{tabular}{c|cc}
\hline Methods: Ref $[28]$ & Minimum $\operatorname{Cost}(\$ / h)$ & Average Cost $(\$ / h)$ \\
\hline CEP & 123488.29 & 124793.48 \\
FEP & 122679.17 & 124119.37 \\
MFEP & 122647.57 & 123489.74 \\
IFEP & 122624.35 & 123382.00 \\
EGA & 122022.96 & 122942.66 \\
FIA & 121823.80 & 122662.48 \\
SPSO & 121787.39 & 122474.40 \\
QPSO & 121448.21 & 122225.07 \\
\hline Proposed Approach: IABC & $\mathbf{1 2 1 4 1 4 . 7 4 9}$ & $\mathbf{1 2 1 4 2 3 . 1 4 5}$ \\
\hline
\end{tabular}

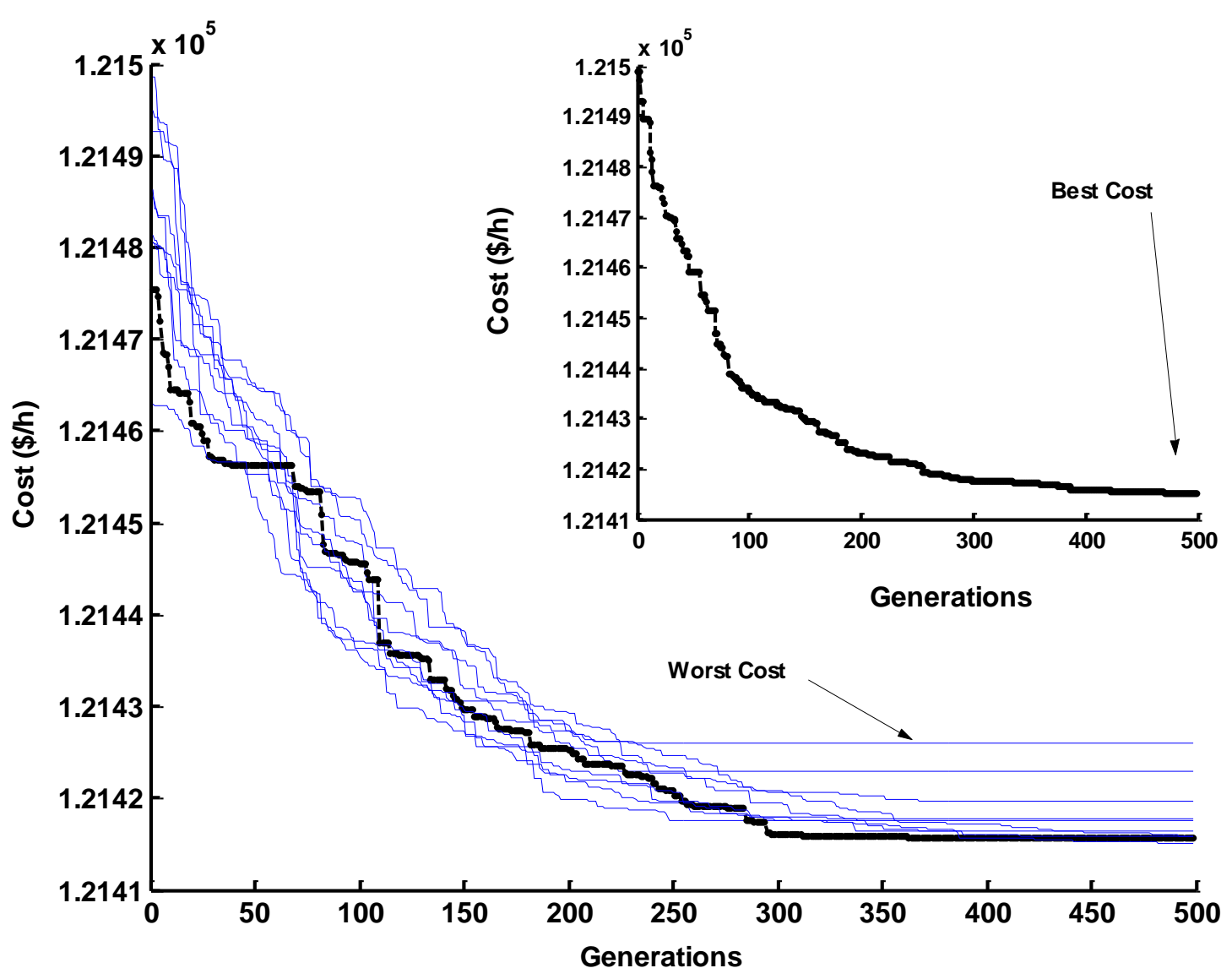

Fig. 7. Convergence characteristic: test system 3: 40 generating units.

\section{CONCLUSION}

In this paper, a new variant algorithm based artificial bee colony termed IABC has been successfully adapted and applied for solving practical economic dispatch taking into account the nonlinear generator characteristics such as valve-loading effects. A new coordinated local search mechanism (LSM) associated to the original ABC algorithm; it allows exploiting effectively the promising region to locate the best solution. The performance of the proposed approach has been tested with three standard test systems: the 13 generating units with valve point effect, and to the large electrical test system, 40 generating units considering the valve-point loading effects. The results of the proposed strategy compared with many recent global optimization methods. It is observed that the proposed variant based $\mathrm{ABC}$ is capable to improving the solution of large economic dispatch considering practical generator constraints.

\section{REFERENCES}

[1] S. Frank, I. Steponavice, and S. Rebennak, "Optimal power flow: a bibliographic survey I, formulations and deterministic methods," Int. J. Energy.System (SpringerVerlag), 2012. 
[2] J. Wood and B. F. Wollenberg, Power Generation, Operation, and Control, 2nd ed. New York: Wiley, 1984.

[3] J. A. Momoh and J. Z. Zhu, "Improved interior point method for OPF problems," IEEE Trans. Power Syst. , vol. 14, pp. 1114-1120, Aug. 1999.

[4] M. Huneault, and F. D. Galiana, "A survey of the optimal power flow literature,” IEEE Trans. Power Systems, vol. 6, no. 2, pp. 762-770, May 1991.

[5] C.-L. Chiang, "Improved genetic algorithm for power economic dispatch of units with valve-point effects and multiple fuels," IEEE Trans. Power Syst., vol. 20, no. 4, pp. 1690-1699, Nov. 2005.

[6] Z. L. Gaing, "Particle swarm optimization to solving the economic dispatch considering the generator constraints," IEEE Trans. Power Systems, vol. 18, no. 3, pp. 1187-1195, 2003.

[7] S.Hui, "Multi-objective optimization for hydraulic hybrid vehicle based on adaptive simulated annealing genetic algorithm," Engineering Applications of Artificial Intelligence 2010; 23(1):27e33.B.

[8] W. M, Lin, F. S., Cheng, and M. T. Tsay, "An improved tabu search for economic dispatch with multiple minima," IEEE Trans. Power Systems, vol. 17, no. 1, pp. 108-112, 2002.

[9] M. F. Mustafar, I. Musirin, M. R. Kalil, M. K. Idris, ”Ant colony optimization (aco) based technique for voltage control and loss minimization using transformer tap setting," In: Proc. 5th student conference on research and development SCOReD 2007. 2007. p. 1-6.

[10] K. Price, R. Storn, and J. Lampinen, Differential Evolution: A Practical Approach to Global Optimization. Berlin, Germany: Springer- Verlag, 2005.

[11] S. Frank, I. Steponavice, and S. Rebennak, "Optimal power flow: a bibliographic survey II, non-deterministic and hybrid methods," Int. J. Energy.System (Springer-Verlag), 2012.

[12] T. Niknam, M. R. Narimani, Rasoul.A. Abarghooee "A new hybrid algorithm for optimal power flow considering prohibited zones and valve point effect," Energy Conversion and Management, vol. 53, pp. 197-206, 2012.

[13] S. Sivasubramani, K. S., Swarup, "Environmental economic dispatch using multi-objective harmony search algorithm," Int. J. Electr. Power System Res, vol. 81, pp. 1778-1785, 2011.

[14] A. Bhattacharya, and P. k, Chattopadhyay "Solving complex economic load dispatch problems using biogeography-based optimization," International Journal of Expert Systems with Apllications, Vol. 37, pp. 3605-3615, 2010.

[15] T. Niknam, H. D. Mojarrad, H. Z. Meymand, B. B. Firouzi, "A new honey bee mating optimization algorithm for nonsmooth economic dispatch," International Journal of Energy, Vol. 36, pp. 896-908, 2011.

[16] Mandal B, Roy PK. "Optimal reactive power dispatch using quasi-oppositional teaching learning based optimization," Int J Electric Power Energy Syst, ;53:12334. 2013

[17] Ahmad Moghadam, Ali Reza Seifi, "Fuzzy-TLBO optimal reactive power control variables planning for energy loss minimization," Energy Conversion and Management, vol. 77, pp. 208-215, 2014.

[18] D. Karaboga, "An idea based on honey bee swarm for numerical optimization," Technical Report-TR06, Erciyes University of Engineering, Faculty of Computer Engineering Department, 2005
[19] D. Karaboga, B. Basturk, "A powerful and efficient algorithm for numeric optimization: artificial bee colony (ABC) algorithm,” J. Global Optim. 39 (3) (2007) 459-471.

[20] B. Akay , D. Karaboga, "A modified Artificial Bee Colony algorithm for real-parameter optimization," Journal of Information Sciences, 2010.

[21] B. Mahdad, T. Bouktir, K. Srairi, "OPF with Environmental Constraints with SVC Controller using Decomposed Parallel GA: Application to the Algerian Network," Journal of Electrical Engineering \& Technology, Korea, Vol. 4, No.1, pp. 55 65, March 2009.

[22] B. Mahdad, K. Srairi "Differential evolution based dynamic decomposed strategy for solution of large practical economic dispatch," 10th EEEIC International Conference on Environment and Electrical Engineering, Italy, 2011.

[23] J. G. Vlachogiannis, and K. Y. Lee, "Economic dispatch-A comparative study on heuristic optimization techniques with an improved coordinated aggregation-based PSO," IEEE Trans. Power Systems, vol. 24, no. 2, pp. 991-1001, 2009.

[24] J. S. Al-Sumait, J. K. Sykulski, A. K. AlOthman, "Solution of different types of economic load dispatch problems using a pattern search method ," Int. J. Electr. Power Components and Systems, vol. 36, no. 3, pp. 250-265, 2008.

[25] Ke. Meng, H. G. Wang, Z. Y. Dong, and K. P. Wong, "Quantum-inspired particle swarm optimization for valvepoint economic load dispatch," IEEE Trans. Power Systems, vol. 25, no. 1, pp. 215-222, 2010.

\section{Authors' Profiles}

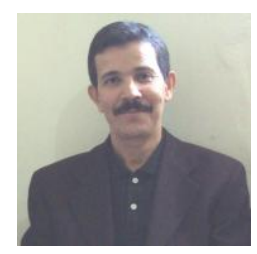

Belkacem Mahdad was born in Biskra, Algeria. He received the B.Sc degree in Electrical Engineering (Power system) from Biskra University Algeria in 1990, MSc degree from Annaba University in 2000, and $\mathrm{PhD}$ from Biskra University, Algeria in 2010. His areas of interest are: FACTS modelling and integration in practical power system, application of metaheuristic techniques to improve the solution of the multi-objective OPF, dynamic economic dispatch, voltage stability and reactive power planning considering FACTS and renewable energy.

Email: bemahdad@mselab.org

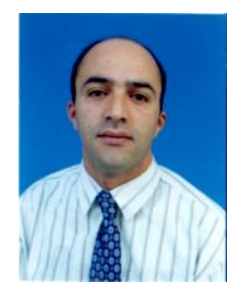

Kamel Srairi was born in Batna, Algeria, in 1967. He received the B.Sc. degree in Electrical Engineering, in 1991, from the University of Batna, Algeria; the M.Sc. degree in Electrical and Computer Engineering, from the National Polytechnic Institute of Grenoble, France, in 1992; and the Ph.D. degree also in Electrical and Computer Engineering, from the University of Nantes, France, in 1996. After graduation, he joined the University of Biskra, Algeria, in 1998 where he is a Professor in the Electrical Engineering Department. His main research interests include analysis, design, and magnetic modeling.

Email: ksrairi@yahoo.fr 